\title{
Organisatorische kenmerken, factoren en verbetering van samenwerking in de eerstelijnszorg
}

\author{
K.E. van Lieshout \\ Maastricht University \\ ke.vanlieshout@student.maastrichtuniversity.nl
}

\section{Samenvatting}

De Nederlandse gezondheidszorg kent steeds meer problemen zoals aanbod dat niet aansluit op de vraag, te hoge zorgkosten en onvoldoende kwaliteit (Vleugels, 2005). Er worden veel strategieën ontwikkeld om deze knelpunten weg te nemen. Een daarvan is het vormen van een zorgketen, een voorbeeld van integrated care. Integrated care is een meer gecoördineerde en geïntegreerde vorm van zorgverlening en leidt tot verschillende gezondheidszorggerelateerde uitkomsten zoals een hogere kwaliteit van zorg, meer efficiëntie en betere toegankelijkheid (Gröne \& Garcia-Barbero, 2002). Samenwerking tussen zorgprofessionals is essentieel voor de levering van integrated care. Zonder afstemming en coördinatie tussen professionals kan er nooit sprake zijn van integrated care. Er zijn veel verschillende organisatorische kenmerken, factoren die samenwerking beïnvloeden en mogelijke maatregelen die samenwerking tussen zorgverleners kunnen verbeteren. Deze kenmerken, factoren en maatregelen moeten in kaart worden gebracht om vast te kunnen stellen waar het bij de samenwerking tussen zorgverleners fout, maar ook goed gaat, om zo de levering van integrated care te kunnen verbeteren. In dit thesisonderzoek zijn deze kenmerken, factoren en verbetermaatregelen onderzocht binnen twee zorgcentra in de eerstelijnszorg. Een secundaire analyse van bestaande data is uitgevoerd. Data zijn verzameld door middel van semi-gestructureerde interviews met zorgprofessionals van verschillende disciplines uit twee zorgcentra. De interviewtranscripten zijn geanalyseerd door middel van een datamatrix. Organisatorische kenmerken van samenwerking in de twee centra zijn: werken met een wijkgerichte samenwerkingsvorm, het hebben van een gezamenlijke organisatie en samen werken in een keten. Factoren die een rol spelen bij de samenwerking zijn: korte lijnen, open deuren, afwezigheid, weinig inhoudelijke overlap, geen overleg, onbekende regelgeving, privacy regelgeving, bureaucratie, elkaar en elkaars werk kennen, vertrouwen en werken met protocollen. Veel voorkomende problemen zijn: hoge werkdruk, geen vast overleg, 
afwezigheid bij overleg en de 'eenmanszaak' cultuur. Verbetermaatregelen zijn: werken met protocollen, structureel overleg en het stimuleren van informeel contact. Inzicht in bovenstaande kenmerken, factoren en verbetermaatregelen van samenwerking leidt tot betere samenwerking tussen zorgprofessionals en dus tot betere levering van integrated care, dat weer leidt tot betere gezondheidszorggerelateerde uitkomsten.

\section{Kernbegrippen}

Integrated care, samenwerking, organisatorische kenmerken, factoren, verbetermaatregelen, eerstelijnszorg

\section{Introductie}

De huidige gezondheidszorg kent steeds meer problemen. Het aanbod sluit niet aan op de vraag, de zorgkosten zijn te hoog en de geleverde kwaliteit is onvoldoende. Daarnaast zal Nederland te kampen krijgen met een dubbele vergrijzing en verschijnen 'minder handen aan het bed'. Kortom, de huidige gezondheidszorg is in crisis (Vleugels, 2005). Er worden veel strategieën ontwikkeld om deze knelpunten weg te nemen. Een daarvan is het vormen van een zorgketen, een voorbeeld van integrated care. Zorgketens zijn 'vormen van geïnstitutionaliseerde regionale of lokale samenwerking van instellingen en beroepsbeoefenaren, gericht op het faciliteren van de samenwerking op uitvoerend niveau met het doel te komen tot een samenhangend, integraal aanbod voor (specifieke) patiëntencategorieën' (Raad voor Volksgezondheid \& Zorg, 1998). Integrated care is een meer gecoördineerde en geïntegreerde vorm van zorgverlening en leidt tot verschillende gezondheidszorggerelateerde uitkomsten zoals een hogere kwaliteit van zorg, meer efficiëntie en betere toegankelijkheid (Gröne \& Garcia-Barbero, 2002). Integrated care vereist afstemming tussen verschillende zorgverleners. Zonder deze afstemming is er geen sprake van integrated care omdat er zonder afstemming nooit een samenhangend, integraal aanbod van zorg voor specifieke patiëntencategorieën tot stand kan komen. Deze afstemming tussen zorgverleners is een minimale vereiste, beter nog zou zijn de aanwezigheid van samenwerking tussen verschillende zorgverleners (Van Raak, 2015).

Deze thesis beschrijft een secundaire analyse van bestaande data over samenwerking binnen gezondheidscentra Hoensbroek-Noord en de Linde. De data is twee jaar geleden verzameld in het onderzoek 'Wijkgericht werken en integrale zorg' (WW\&IZ onderzoek). Dit onderzoek presenteert de opvattingen van eerstelijnszorgprofessionals, gemeenten, zorgverzekeraars en patiënten op het integreren van gemeentelijke basiszorg en eerstelijnszorg binnen verschillende gezondheidscentra. Onderzocht is hoe 
gezondheidscentra de multidisciplinaire samenwerking binnen de eerstelijnszorg kunnen versterken en hoe gemeentelijke basiszorg en eerstelijnszorg beter op elkaar kunnen worden afgestemd.

Deze thesis richt zich op organisatorische kenmerken van samenwerking, factoren die een rol spelen bij de samenwerking en mogelijke maatregelen om deze samenwerking beter te laten verlopen. Integrated care (geïntegreerde zorg) is het hoofdthema waaronder deze organisatorische kenmerken, factoren en maatregelen vallen. De probleemstelling is als volgt geformuleerd: 'Wat zijn de organisatorische kenmerken van samenwerking, welke factoren spelen een rol bij de samenwerking en welke mogelijke maatregelen zijn denkbaar voor het verbeteren van de samenwerking binnen gezondheidscentra Hoensbroek-Noord en de Linde?' Deze probleemstelling is uitgesplitst in drie onderzoeksvragen.

\section{Methoden}

Een secundaire analyse van bestaande data, dat is verzameld tijdens het 'Wijkgericht werken en integrale zorg' onderzoek (WW\&IZ onderzoek), is uitgevoerd. Het WW\&IZ onderzoek is kwalitatief van aard en maakte gebruik van een case study design. Zes eerstelijnszorgcentra uit drie gemeenten in de Regio Parkstad (Zuid-Limburg) hebben deelgenomen aan het onderzoek. De zorgcentra (cases) zijn gekozen door hun diversiteit in het integraal aanbieden van zorg. Data zijn verzameld door het gebruik van verschillende methoden. Ten eerste zijn er eerstelijns zorgprofessionals $(n=57)$, mensen werkzaam bij gemeenten $(n=11)$ en mensen werkzaam bij een zorgverzekeraar $(n=3)$ geïnterviewd. Er is gebruik gemaakt van semi-gestructureerde interviews. Ten tweede is er een focusgroep bij patiënten $(n=6)$ afgenomen waarin verschillende aspecten in relatie tot samenwerking zijn onderzocht. Deze aspecten zijn onder te verdelen in financiële, organisatorische, culturele, fysieke en inhoudelijke aspecten. Ten derde zijn vragenlijsten bij patiënten afgenomen (het aantal is onbekend) om zo inzicht te verkrijgen in hoeverre patiënten de mate van geïntegreerde zorg ervaren.

Tijdens de secundaire analyse zijn van twee gezondheidscentra (Hoensbroek-Noord en de Linde) transcripten van interviews geanalyseerd. De interviewtranscripten zijn geanalyseerd door middel van een datamatrix die is samengesteld met theorieconcepten met betrekking tot samenwerking. De theorie bestaat uit het WIZ-model en modellen van het NIVEL (Nederlands instituut voor onderzoek van de gezondheidszorg) en het LOVE (landelijk overleg versterking eerste lijn). Theorie vormt de schakel tussen de onderzoeksvragen en de data en is van groot belang (Van Raak \& Paulus, 2002). Tijdens 
de secundaire analyse is er gebruik gemaakt van inductieve axiale codering. Er is gezocht naar consistentie en inconsistentie tussen zorgcentra en tussen respondenten.

Organisatorische kenmerken van samenwerking zijn kenmerken van de structuur en vorm van de organisatie en hierbij kan ten eerste gedacht worden aan de typen organisatorische samenwerkingsvormen beschreven door het NIVEL (2009). Het NIVEL onderscheidt drie hoofdvarianten: (1) organisatievormen die geïntegreerde zorg op populatieniveau omvatten; (2) organisatievormen die de zorg rond een bepaalde patiëntengroep integraal aanbieden; en (3) organisatievormen die zich richten op het organiseren van de managementfunctie op een praktijkoverstijgend niveau (NIVEL, 2009). Naast het NIVEL, onderscheidt het LOVE ook verschillende typen organisatorische samenwerkingsvormen. Het LOVE beschrijft vier basisvormen van samenwerking, namelijk: (1) afstemming; (2) projectmatig samenwerken; (3) samen werken in een keten; en (4) een gezamenlijke organisatie (LOVE, 2015).

Het WIZ-model, ontwikkeld door de werkgroep integrale zorg (WIZ) van de Universiteit Maastricht, beschrijft bevorderende en belemmerende factoren van samenwerking (Van Raak, 2008). Een blijvende vorm van samenwerking wordt volgens het model beïnvloed door clusters van factoren of dimensies. De volgende clusters: lokale context, externe factoren, determinanten en uitingsvormen van draagvlak en verandermanagement zijn bipolair. Positief geformuleerd werkt een factor bevorderend, negatief geformuleerd werkt deze belemmerend (Bohlmeijer et al., 2005).

Samenwerkingsproblemen kunnen worden gekoppeld aan vier typen slaagfactoren (individuele hulpverleners, sociale context, organisatorische context en economische/ juridische context) van het LOVE (2015) met bijbehorende maatregelen ter verbetering van de samenwerking. Daarnaast zijn er respondenten geweest die zelf met oplossingen kwamen.

\section{Resultaten}

Onderzoeksvraag 1 (organisatorische kenmerken van samenwerking)

Organisatorische kenmerken van samenwerking die het vaakst voorkomen binnen de twee centra zijn: (1) de samenwerkingsvorm die wordt toegepast; en (2) verschillende vormen van samenwerking. Respondenten (100\% binnen beide centra) geven aan te werken met een wijkgerichte samenwerkingsvorm. Bij de verschillende soorten samenwerking scoort het werken met een gezamenlijke organisatie het hoogste $(100 \%$ 
binnen beide centra), gevolgd door het samen werken in een keten (100\% HN en 90\% DL) en afstemming ( $80 \%$ bij beide centra). Deze scores zijn te verwachten gezien het hoofddoel van de centra, namelijk een geïntegreerd geheel van multidisciplinaire zorg aanbieden op populatieniveau. Afstemming wordt onder andere omschreven als 'afstemming over patiënten door verschillende professionals' (respondent 1a) en 'teamoverleg' (respondent $7 b)$. Projectmatig werken komt minder vaak voor (20\% HN en $30 \% \mathrm{DL}$ ). Een verschil tussen beide centra is dat binnen Hoensbroek-Noord nog wordt gewerkt met een overkoepelend managementteam (organisatorische samenwerkingsvorm 'management').

\section{Onderzoeksvraag 2 (factoren die een rol spelen bij samenwerking)}

De WIZ-model factoren zijn overwegend gunstig. Gunstige factoren zoals de aanwezigheid van een gemeenschappelijke visie ( $80 \% \mathrm{HN}$ en $70 \% \mathrm{DL}$ ) en korte lijnen $(60 \% \mathrm{HN}$ en $50 \%$ $\mathrm{DL})$ scoren aanzienlijk hoger dan de ongunstige factoren. In gunstige zin springt de factor draagvlak eruit, bij de ongunstige factoren zijn dit de lokale context en externe factoren. Opvallend is dat binnen de Linde ook draagvlak ('eilandjes werken' scoort 40\%) en management factoren (afwezigheid praktijkmanager scoort 30\%) als ongunstig worden beschreven, dit is niet het geval binnen Hoensbroek-Noord. De lokale context factoren zijn naast dat deze vaak als ongunstig worden beschreven ook vaak gunstig.

Binnen Hoensbroek-Noord scoren de bevorderende lokale context en draagvlak factoren het hoogste. Korte lijnen (60\%), open deuren (50\%) en aanwezigheid van een gemeenschappelijke visie (80\%) scoren aanzienlijk hoger dan de rest van de factoren. Binnen de Linde scoren de bevorderende draagvlak en management factoren het hoogste. Aanwezigheid van een gemeenschappelijke visie scoort $70 \%$ en aanwezigheid van een kartrekker scoort $80 \%$. Als de twee centra met elkaar vergeleken worden valt op dat binnen Hoensbroek-Noord geen belemmerende draagvlak en management factoren worden genoemd. De externe- en draagvlak factoren komen overeen. De externe factoren worden allemaal als negatief beschouwd.

Er is hier gekozen voor een afkappunt voor relevantie van 50\%. Dit punt dient als hulpmiddel bij de analyses en is niet op statistische overwegingen gebaseerd. Binnen Hoensbroek-Noord scoren bij lokale context factoren drie van de elf factoren (korte lijnen, open deuren en regelgeving niet kennen) $50 \%$ of hoger. Bij de Linde is dit één van de elf factoren (korte lijnen). Bij externe factoren scoort Hoensbroek-Noord met één van de vier 34 factoren 50\% of hoger (regelgeving niet kennen scoort 50\%). De Linde scoort daar met alle vier de factoren onder het relevantie afkappunt. Hoensbroek-Noord scoort met hun 
enige draagvlakfactor (gemeenschappelijke visie) $80 \%$. De Linde scoort met één van de twee draagvlakfactoren (gemeenschappelijke visie) boven het relevantie afkappunt. Bij management factoren scoort Hoensbroek-Noord met geen van de vijf factoren $50 \%$ of hoger. De Linde scoort daar met één (aanwezigheid kartrekker) van de drie factoren $50 \%$ of hoger. Als er wordt gekeken naar de positieve scores, scoort Hoensbroek-Noord met meer en hogere scores boven het relevantie afkappunt en scoort het dus gunstiger dan de Linde. In onderstaande alinea zijn de bevindingen per factor uiteengezet en zijn de scores onder het afkappunt van 50\% ter volledigheid ook weergegeven.

De lokale context factor die het meest voorkomt binnen beide centra is de aanwezigheid van korte lijnen (60\% HN en 50\% DL). Binnen Hoensbroek-Noord spelen 'open deuren', gemakkelijk bij elkaar binnen kunnen lopen, een grote rol (50\%) en bij de Linde is dit het ontbreken van een MDO (40\%). Binnen beide centra zijn organisatorische herstructureringen ( $10 \% \mathrm{HN}$ en $20 \% \mathrm{DL}$ ) en eerdere samenwerking ( $10 \%$ bij beide) van minder belang bij samenwerking. Al met al komen de lokale context factoren overeen tussen beide centra. Externe factoren die een rol spelen zijn onbekende regelgeving (50\% $\mathrm{HN}$ en $20 \% \mathrm{DL}$ ), privacyregelgeving ( $20 \% \mathrm{HN}$ en $10 \% \mathrm{DL}$ ) en bureaucratie ( $10 \%$ bij beiden). Het niet kennen van de Wmo regelgeving komt naar voren in dit citaat: 'Nee, een heleboel dingen bij de Wmo zijn voor mij ook dat ik denk van o gaat dat op die manier?' (respondent gb). Verschillend tussen beide centra zijn de factoren 'vergoedingensysteem' (10\% HN) en 'sociaaleconomische spel > patiënt' (10\% DL). Een draagvlakfactor die door bijna alle respondenten genoemd is heeft te maken met het hebben van een gemeenschappelijke visie ( $80 \% \mathrm{HN}$ en $70 \% \mathrm{DL})$. Daarnaast hebben professionals binnen de Linde het 'werken in eilandjes' omschreven als een draagvlakfactor die de samenwerking negatief beïnvloedt. Onder de noemer management worden de aanwezigheid van een kartrekker (40\% HN en $80 \% \mathrm{DL}$ ) en het hebben van een bestuur (30\% HN en $10 \% \mathrm{DL}$ ) als belangrijk ervaren. Daarnaast zijn er nog de bevorderende management factoren: huisarts is spil (10\% HN), aanwezigheid management team $(110 \% \mathrm{HN})$ en platte organisatiestructuur $(10 \% \mathrm{HN})$. Een belemmerende managementfactor is de afwezigheid van een praktijkmanager (30\% DL). Verschillend is dat binnen Hoensbroek-Noord geen belemmerende management factoren genoemd worden.

Naast bovenstaande WIZ-model factoren zijn er nog tal van succesfactoren voor goede samenwerking. De top vijf van beide centra komt erg overeen en bestaat uit: vertrouwen (70\% HN en 60\% DL), informele sfeer (70\% HN en 40\% DL), elkaars werk kennen (60\% HN en $40 \% \mathrm{DL}$ ), werken met een plan/protocol ( $40 \% \mathrm{HN}$ en $50 \% \mathrm{DL}$ ) en elkaar kennen $(50 \% \mathrm{HN}$ 
en $30 \% \mathrm{DL}$ ). Succesfactoren die door beide centra niet zijn erkend zijn: domeinconsensus en onderhandelingsvermogen. Ook hier wordt gewerkt met het relevantie afkappunt van 50\%. Vier (elkaar kennen, onderhandelingsvermogen, vertrouwen en juiste klimaat/sfeer) van de zestien factoren scoren binnen Hoensbroek-Noord 50\% of hoger. Bij de Linde is dit twee (methodisch/planmatig werken en vertrouwen) van de negentien. Gezien de scores, scoort ook hier Hoensbroek-Noord positiever dan de Linde.

Problemen met betrekking tot organisatie/management overheersen de andere twee typen (visie/strategie/doelen en cultuur/gedrag/omgangsvormen). Gezien het relevantie afkappunt van $50 \%$, is de afwezigheid van vaste overlegmomenten $(50 \% \mathrm{DL}$ ) de enige relevante organisatie/management factor. Dit is gelijk ook de enige factor boven het relevantie afkappunt. Hoensbroek-Noord scoort met geen factoren boven het relevante afkappunt. Daarnaast zijn er binnen Hoensbroek-Noord veertien problemen gesignaleerd terwijl dit er binnen de Linde eenentwintig ( $50 \%$ meer) zijn. De Linde scoort dus hoger dan Hoensbroek-Noord als het gaat om samenwerkingsproblemen. Dit komt overeen met het beeld dat naar voren komt in bovenstaande resultaten. Ter volledigheid zijn ook hier de samenwerkingsproblemen per type uiteengezet.

Voorkomende samenwerkingsproblemen met betrekking tot visie/strategie/doelen zijn: geen concreet beleid (10\% DL), geen inhoudelijke overlap met gemeente (10\% DL), onduidelijkheid over visie/doelen gemeente $(10 \% \mathrm{DL}$ ) en praktijk niet als prioriteit hebben (10\% DL). Opvallend is dat binnen Hoensbroek-Noord geen samenwerkingsproblemen met betrekking tot visie/strategie/doelen naar voren zijn gekomen. Met betrekking tot organisatie en management komen er tal van factoren naar voren, waarvan de belangrijkste hoge werkdruk ( $40 \% \mathrm{HN}$ en $20 \% \mathrm{DL}$ ) en geen vaste overlegmomenten (50\% DL) zijn. Dit zijn ook gelijk de meest erkende problemen binnen de centra. Bij de cultuur/gedrag/omgangsvormen problemen komt het probleem van een 'eenmanszaak of eigen toko cultuur' overeen ( $20 \% \mathrm{HN}$ en $10 \% \mathrm{DL}$ ) en zijn er verder veel verschillende problemen. Voorbeelden hiervan zijn elkaar niet kennen (10\% DL), niet op de hoogte zijn van vernieuwingen $(10 \% \mathrm{HN})$ en te weinig informeel contact $(10 \% \mathrm{DL})$.

Bovenstaande resultaten schetsen een beeld waarin Hoensbroek-Noord positiever naar voren komt dan de Linde en dus gunstigere factoren heeft met betrekking tot samenwerking. 


\section{Onderzoeksvraag 3 (maatregelen ter verbetering van samenwerking)}

Samenwerkingsproblemen met betrekking tot visie/strategie/doelen, zoals het ontbreken van een gemeenschappelijke visie en concreet beleid, kunnen worden verholpen door een combinatie van verschillende typen slaagfactoren. Onderlinge samenwerking, duidelijkheid over effecten en aanwezigheid van regie bieden oplossing. Respondenten binnen de Linde geven daarnaast aan dat een gezamenlijke centrum folder kan helpen met het uitdragen van een gemeenschappelijke visie.

Samenwerkingsproblemen met betrekking tot organisatie/management zijn veel voorkomend binnen beide centra. Oplossingen zijn divers en bestaan ook hier uit een combinatie van verschillende soorten slaagfactoren. Hoge werkdruk (40\% HN en $20 \%$ $\mathrm{DL}$ ) kan worden verholpen door de aanwezigheid van regie en goede informatiestromen, duidelijkheid over samenwerking en afbakening van taken. Het niet hebben van vaste overlegmomenten $(50 \% \mathrm{DL})$ kan worden opgelost door aanwezigheid van protocollen en regie en het inplannen van een structureel multidisciplinair overleg (MDO). Veel respondenten geven aan dat MDO's niet kunnen worden ingepland door de hoge werkdruk dus dat probleem zal daarvoor moeten worden opgelost. Het probleem van werken met verschillende informatiesystemen binnen Hoensbroek-Noord kan volgens een respondent verholpen worden door te werken met één basissysteem dat compatibel is met alle andere systemen.

Cultuur/gedrag/omgangsvormen samenwerkingsproblemen kunnen ook worden verholpen door een combinatie van typen slaagfactoren. Het probleem van een 'eenmanszaak of eigen toko cultuur' ( $20 \% \mathrm{HN}$ en $10 \% \mathrm{DL}$ ) kan worden opgelost door verwachtingen duidelijk te maken. Als iedere professional weet dat van hem of haar verwacht wordt dat hij of zij samenwerkt, zal diegene dat waarschijnlijk ook eerder doen. Daarnaast kan in protocollen worden vastgelegd hoe en wie er samenwerken met betrekking tot een bepaald probleem of patiënt. Elkaar niet kennen $(10 \% \mathrm{DL})$ kan worden verholpen door informeel contact te stimuleren. Dit kan bijvoorbeeld door de aanwezigheid van een koffieruimte waar professionals elkaar tijdens pauzes tegen het lijf lopen.

\section{Conclusie/discussie}

Binnen gezondheidscentra Hoensbroek-Noord en de Linde zijn organisatorische kenmerken van samenwerking: werken met een wijkgerichte samenwerkingsvorm, het hebben van een gezamenlijke organisatie, samen werken in een keten en afstemming. Bevorderende factoren van samenwerking zijn: korte lijnen, aanwezigheid van een gemeenschappelijke 
visie, aanwezigheid van een kartrekker, het hebben van een bestuur, aanwezigheid van vertrouwen, elkaar en elkaars werk kennen, informele sfeer en werken met een plan/ protocol. Belemmerende factoren zijn: onbekende regelgeving, privacyregelgeving, bureaucratie, geen concreet beleid, geen inhoudelijke overlap met gemeente, onduidelijkheid over visie/doelen van de gemeente, praktijk niet als prioriteit hebben, hoge werkdruk, geen vaste overlegmomenten en het probleem van een 'eenmanszaak of eigen toko cultuur'. Mogelijke maatregelen ter verbetering van de samenwerking zijn: onderlinge samenwerking, duidelijkheid over effecten, aanwezigheid van regie, goede informatiestromen, duidelijkheid over samenwerking, afbakening van taken, protocollen, het inplannen van structureel overleg, duidelijk maken van verwachtingen en informeel contact stimuleren.

Over de theorie kan vermeld worden dat deze over het algemeen goed aansluit bij de onderzoeksvragen en antwoorden van de respondenten. De typen organisatorische samenwerkingsvormen van het NIVEL (2009) en de basisvormen van samenwerking door het LOVE (2015) kwamen naar voren in de transcripten en geven een goed beeld van vormen van samenwerking binnen de zorgcentra. Het WIZ-model (2008) is een handig instrument gebleken om factoren van samenwerking te identificeren en categoriseren. De succesfactoren en samenwerkingsproblemen van het LOVE (2015) waren een goede aanvulling daarop. Er is gebruik gemaakt van verschillende theorieën omdat deze theorieën elkaar aanvullen en dus een uitgebreider en meer valide beeld van factoren geven. De validiteit van de secundaire analyse is voldoende om geldige conclusies te kunnen trekken. In de datamatrix (analyse-instrument) is gebruik gemaakt van verschillende constructen (theorieën) dat de begripsvaliditeit verhoogt. Beter was geweest om de data-analyse te laten uitvoeren door meerdere personen die dit onafhankelijk van elkaar doen en door middel van discussie inconsistenties oplossen. Ook zijn er wegens tijdgebrek twee van de zes zorgcentra geanalyseerd. Om een uitgebreider en betrouwbaarder beeld te krijgen van factoren, kenmerken en maatregelen dienen er meer dan twee zorgcentra geanalyseerd te worden. Daarnaast zijn tijdens de secundaire analyse alleen de interviewtranscripten geanalyseerd, beter zou zijn om daarnaast ook de beschikbare data van de focusgroep en vragenlijsten te analyseren. Dit alles is niet bevorderlijk voor de betrouwbaarheid.

Dit onderzoek geeft inzichten op het gebied van samenwerking. Dit is van belang om de levering van integrated care te kunnen verbeteren, dat de zorg ten goede komt. Integrated care draait om samenwerking tussen verschillende zorgprofessionals. Zonder deze samenwerking is er geen sprake van integrated care. Inzicht in organisatorische 
kenmerken van samenwerking en factoren die een rol spelen bij samenwerking binnen de gezondheidscentra laat zien welke samenwerkingsvormen en factoren wel/niet werken. Bovendien laten de maatregelen zien hoe samenwerkingsproblemen opgelost kunnen worden. (Beleids)medewerkers kunnen hier hun voordeel uit halen en zorgen dat hun gezondheidscentrum de juiste kenmerken krijgt.

\section{Rol van de student}

Kristie van Lieshout, derdejaars bachelorstudent gezondheidswetenschappen, heeft in een thesiskring onder begeleiding van Arno van Raak gewerkt aan haar thesisonderzoek. Het onderwerp was voorgesteld door haar begeleider en hij heeft ook een bestaande dataset aangeleverd. Het design en uitvoering van de secundaire analyse evenals de formulering van de conclusies en het schrijfwerk is uitgevoerd door de student.

\section{Dankwoord}

Bij dezen wil ik mijn begeleider bedanken voor de goede begeleiding en ondersteuning tijdens mijn thesisperiode. Met zijn feedback kwam ik altijd weer op het juiste pad. Daarnaast wil ik Annelies bedanken voor de goede samenwerking. Het is altijd fijn je verhaal kwijt te kunnen aan iemand die in hetzelfde schuitje zit en om samen naar oplossingen te zoeken.

\section{Referenties}

1. Bohlmeijer, E., Ruland, E., Mur-Veeman, I, \& Van Raak, A. (2005). Procesmanagement in public health, analyse, ontwerp \& verandering. Utrecht: Trimbos-instituut.

2. Gröne, O., \& Garcia-Barbero, M. (2002). Trends in integrated care: reflections on conceptual issues. Kopenhagen: World Health Organization.

3. Landelijk overleg versterking eerstelijnszorg (2015). Samenwerken in de eerste lijn. Een handreiking voor zorgverleners. Gedownload 28 april, 2015, van http://www.samenwerkeneerstelijnszorg.nl/scrivo/asset. php?id $=567665$

4. Nederlands Instituut voor onderzoek van de gezondheidszorg (2009). Organisatorische samenwerkingsverbanden binnen de eerste lijn - een verkenning. Gedownload 28 april, 2015, van http://www.nivel.nl/sites/default/files/bestanden/rapport-organisatorischesamenwerkingsverband en-eerste-lijn.pdf

5. Raad voor Volksgezondheid \& Zorg (1998). Redesign van de eerste lijn in transmuraal perspectief. Opgehaald 13 april, 2015, van http://rvz.net/uploads/docs/Redesign_van_de_eerste_lijn_in_ transmuraal_perspectief.pdf

6. Van Raak, A. \& Paulus, A. (2002). Onderzoek doen in de zorg. Handboek voor de opzet en uitvoering 
van onderzoek naar beleids- en managementvraagstukken in de gezondheidszorg. Maarssen: Elsevier gezondheidszorg.

7. Van Raak, A. (2008). Beschrijving van het WIZ-model. Gedownload op 30 april, 2015, van https:// eleum.unimaas.nl/bbcswebdav/pid-437470-dt-content-rid-1664354_1/courses/2014-300-BMZ3001/ BMZ3001\%202014- 2015\%20Beschrijving\%20WIZ-Model.pdf

8. Van Raak, A. (2015). College: wat is integrated care?. Gedownload 13 april, 2015, van https://eleum.unimaas. nl/bbcswebdav/pid-437496-dt-content-rid-1783998_1/courses/2014-300-BMZ3001/BMZ3001\%2020142015\%20Wat\%2ois\%2ointegrated\%20care-EleUM\%281\%29.pdf

9. Van Staa, A.L., \& Evers, J. (2010). 'Thick analysis': strategie om de kwaliteit van kwalitatieve data-analyse te verhogen. Tijdschrift voor Kwalitatief Onderzoek in Nederland, 43(1), 5-12.

10. Vleugels, A. (2005). Zorg voor de kwaliteit van de zorg. Leuven: Leuven University Press. 